\title{
Prevalence of hypertensive disorders of pregnancy in Ethiopia: a systemic review and meta-analysis
}

Abadi Kidanemariam Berhe ${ }^{1 *}$, Getachew Mullu Kassa ${ }^{2}$, Gedefaw Abeje Fekadu ${ }^{3}$ and Achenef Asmamaw Muche ${ }^{4}$

\begin{abstract}
Background: Although hypertensive disorders of pregnancy are the leading cause of poor perinatal outcomes in Ethiopia, there is no study that shows the national prevalence. Therefore, the aim of this study was to estimate the national pooled prevalence of hypertensive disorders of pregnancy from studies conducted in different parts of the country.
\end{abstract}

Methods: Databases; MEDLINE, PubMed, HINARI, EMBASE, Google Scholar and African Journals Online were searched by using different search terms on HDP and Ethiopia. Joanna Briggs Institute Meta-Analysis of Statistics Assessment and Review Instrument was used for critical appraisal of studies. The analysis was done using STATA 14 software. The Cochran Q test and $P^{2}$ test statistics were used to test heterogeneity of studies. Egger's test was used to show the publication bias. The pooled prevalence of HDP and the odds ratio (OR) with $95 \%$ confidence interval was presented using forest plots.

Result: Seventeen studies were included in this review, with a total of 258,602 pregnant women. The overall pooled prevalence of hypertensive disorders of pregnancy in Ethiopia was 6.07\% (95\% Cl: 4.83\%, 7.31\%). The Subgroup analysis by region and year of study showed a higher prevalence of hypertensive disorders of pregnancy in Southern Nations, Nationalities, and Peoples' Region, $10.13 \%(95 \% \mathrm{Cl}=(8.5,12.43))$, and reduction in the rate of HDP from 1990's to 2010's, $8.54 \%$ reducing to $5.71 \%$ respectively. The pooled prevalence of pregnancy-induced hypertension $(\mathrm{PHH})$ and preeclampsia/eclampsia alone were 6.29 and 5.47 respectively. Pregnant women $\geq 35$ years old are more likely to develop hypertensive disorders of pregnancy, $\mathrm{OR}=1.64(95 \% \mathrm{Cl}=(1.18,2.28))$. No statistically significant difference was observed between HDP and younger maternal age (less than 20 years old); $\mathrm{OR}=2.92$ $(95 \% \mathrm{Cl}=(0.88,9.70))$. There was no association between hypertensive disorders of pregnancy and number of pregnancy, $\mathrm{OR}=1.37(95 \% \mathrm{Cl}=0.78,2.41))$.

Conclusions: The prevalence of hypertensive disorders of pregnancy is high in Ethiopia. The problem is more common among older pregnant women (> 35 years old). Government and other stakeholders should give due attention to an early screening of hypertension during pregnancy.

Keywords: Prevalence, Hypertensive disorders of pregnancy, Preeclampsia, Eclampsia, Systemic review, Metaanalysis, Ethiopia

\footnotetext{
* Correspondence: abadik021@gmail.com

${ }^{1}$ College of Medicine and Health science, Adigrat University, Tigray, Ethiopia

Full list of author information is available at the end of the article
} 


\section{Background}

While motherhood is a positive and enjoyable experience, many women are experiencing suffering, illness, and death. Around 15\% of pregnant women are expected to develop life-threatening complications during pregnancy, at delivery or post-partum. Hypertensive disorders of pregnancy(HDP) are significant contributors to these complications and sufferings [1-3].

A pregnant woman is considered hypertensive if her blood pressure is greater than or equal to $140 / 90 \mathrm{mmHg}$ on two consecutive measurements [4]. Hypertensive disorders of pregnancy is a general term for increased blood pressure during pregnancy. It includes pregnancyinduced hypertension (PIH) (without proteinuria), preeclampsia (with proteinuria) and eclampsia (preeclampsia with convulsions), gestational hypertension and chronic hypertension [5].

Hypertensive disorders of pregnancy are public health problems globally. Global studies showed that preeclampsia and eclampsia were associated with higher rates of maternal mortality, prenatal mortality, and morbidity, preterm and small for gestational age deliveries. Women with HDP are five times more likely to have perinatal death compared with women who have no hypertensive disorders of pregnancy [6-9].

Pregnancy-induced hypertension complicates $10 \%$ of all pregnancies. Around 40,000 women, mostly from developing countries, die each year due to preeclampsia or eclampsia. Preeclampsia alone is estimated to account for about $40 \%$ to $60 \%$ of maternal deaths in developing countries [10-13]. A hospital-based study conducted in South Africa showed that HDP contributed for $20.7 \%$ of maternal deaths in the country [11].Hypertensive disorders of pregnancy accounts for $19 \%$ of maternal deaths in Ethiopia [14].

The Antenatal care (ANC) is one of the maternal care services in Ethiopia. Blood pressure measurement and urine tests for protein urea are among the components of routine ANC. According to the 2016 Ethiopian demographic and health survey (EDHS) report, 62\% of pregnant women had at least one ANC visit. From this, 75\% of pregnant women had their blood pressure measured and $66 \%$ had a urine test [11].

The prevalence of preeclampsia in developing countries ranges from $1.8 \%$ to $16.7 \%$ [10]. The incidence of HDP was estimated $9.8 \%$ in a study conducted in South Africa [11]. The prevalence of HDP in Ethiopia ranges from $1.2 \%$ to $18.25 \%$ according to various studies conducted [15-31].These studies are inconsistent and inconclusive to show the national magnitude. The country level estimate is essential to design evidence-based interventions. Therefore, this systematic review and metaanalysis was designed to estimate the national pooled prevalence of hypertensive disorders of pregnancy in Ethiopia and regions.

\section{Methods}

\section{Study design and search strategy}

A systemic review and meta-analysis was conducted from published and unpublished researches on the prevalence of hypertensive disorders of pregnancy in Ethiopia. The studies were retrieved through internet search from the databases of MEDLINE, PubMed, EMBASE, HINARI, Google Scholar and the African Journals Online (AJOL). The search was done using the following search terms; prevalence, hypertensive disorders of pregnancy, gestational hypertension, preeclampsia, eclampsia, Pregnancyinduced hypertension, and Ethiopia. The reference lists of already identified studies were screened to retrieve additional articles. All published articles up to16 December 2016 were included in this review. Unpublished studies were retrieved from Addis Ababa University electronic library and by requesting authors [32].

\section{Eligibility criteria}

Studies were included in the review if the study;

1) design was cross-sectional, cohort, case-control or trial

2) was conducted on hypertensive disorders of pregnancy in Ethiopia

3) used the standard definition for classification of HDP (described in the outcome of interest)

4) was published in English

\section{Definition of outcomes of interest}

- The primary outcome of this study is the prevalence of Hypertensive disorders of pregnancy. It is defined as a Systolic blood pressure (SBP) of $140 \mathrm{mmHg}$ or more or diastolic blood pressure (DBP) of $90 \mathrm{mmHg}$ or more on 2 or more consecutive occasions during pregnancy $[33,34]$.

- Eclampsia is defined as the occurrence of convulsions; DBP of $90 \mathrm{mmHg}$ or higher after 20 weeks of pregnancy; proteinuria of $2+$ or higher; and signs and symptoms of severe pre-eclampsia [19].

- Pre-eclampsia denotes for women who develop both hypertension and proteinuria in pregnancy [33].

- Gestational hypertension is defined as an elevation of DBP to $90 \mathrm{mmHg}$ or more without proteinuria in a previously normotensive non-protein uric pregnant woman [33].

- Chronic hypertension in pregnancy is made on the finding of hypertension; at the first "booking visit" before the 20th week of pregnancy in the absence of trophoblastic disease or at any stage of pregnancy in women with proven chronic hypertension or which then persists more than 42 days after delivery [33]. 
The secondary outcome of interest of this review was association of HDP with maternal factors. These factors include; maternal age, which is categorized as young maternal age (less than 20 years), adult mothers (20-34 years old), and older mothers (aged $\geq 35$ years) Gravidity in this review is categorized into; primigravida and multigravida. Primigravida is defined as women who are pregnant for the first time. Multigravida is women who are pregnant for two or more times.

\section{Data extraction}

The data extraction was done using a tool developed by the 2014 Joanna Briggs Institute Reviewers' Manual data extraction form [35]. The data extraction tool includes information on title, author, year of study, publication, study design, sample size, study participants, study area, response rate, sampling method, and definition used for HDP. Additionally, data collection tool for the number of HDP cases by maternal age (young and older mothers) and gravidity (primigravida and multigravida) was also included.

\section{Quality assessment and data collection}

Joanna Briggs Institute Meta-Analysis of Statistics Assessment and Review Instrument (JBI-MAStARI) was used for critical appraisal of the studies. Retrieved published and unpublished studies were assessed for inclusion using their title and abstract. Then a full review of articles for quality assessment was done before selecting for final review. All authors independently assessed the articles for inclusion in the review. Any discrepancy which arose between the authors on the review process was solved through discussion.

\section{Publication bias and heterogeneity}

The existence of heterogeneity was assessed using $\mathrm{I}^{2}$ and its corresponding P - value. A value of $25 \%, 50 \%$, and $75 \%$ was used to declare the heterogeneity test as low, medium and high heterogeneity. For results with statistically significant heterogeneity, random effect model of analysis was used [36].Egger regression asymmetry test was used to assess the statistical significance of publication bias.

\section{Synthesis of result and statistical analysis}

The data were entered using Microsoft Excel. The metaanalysis was conducted using Stata 14 software. Forest plots were used to present the combined estimate with the 95\% confidence interval $(\mathrm{CI})$. For studies which didn't present standard error (SE), the formula; $\mathrm{SE}=\sqrt{\mathrm{p}} \mathrm{x}(1-\mathrm{p}) / \mathrm{n}$ was used for calculation. The estimated pooled prevalence was computed with $95 \%$ CI. Subgroup analysis was done by region and type of HDP. Additionally, association of HDP with number of pregnancy and maternal age was conducted.

\section{Results}

\section{Studies identified}

A total of 104 articles were retrieved through electronic searching. In addition, one article was obtained by

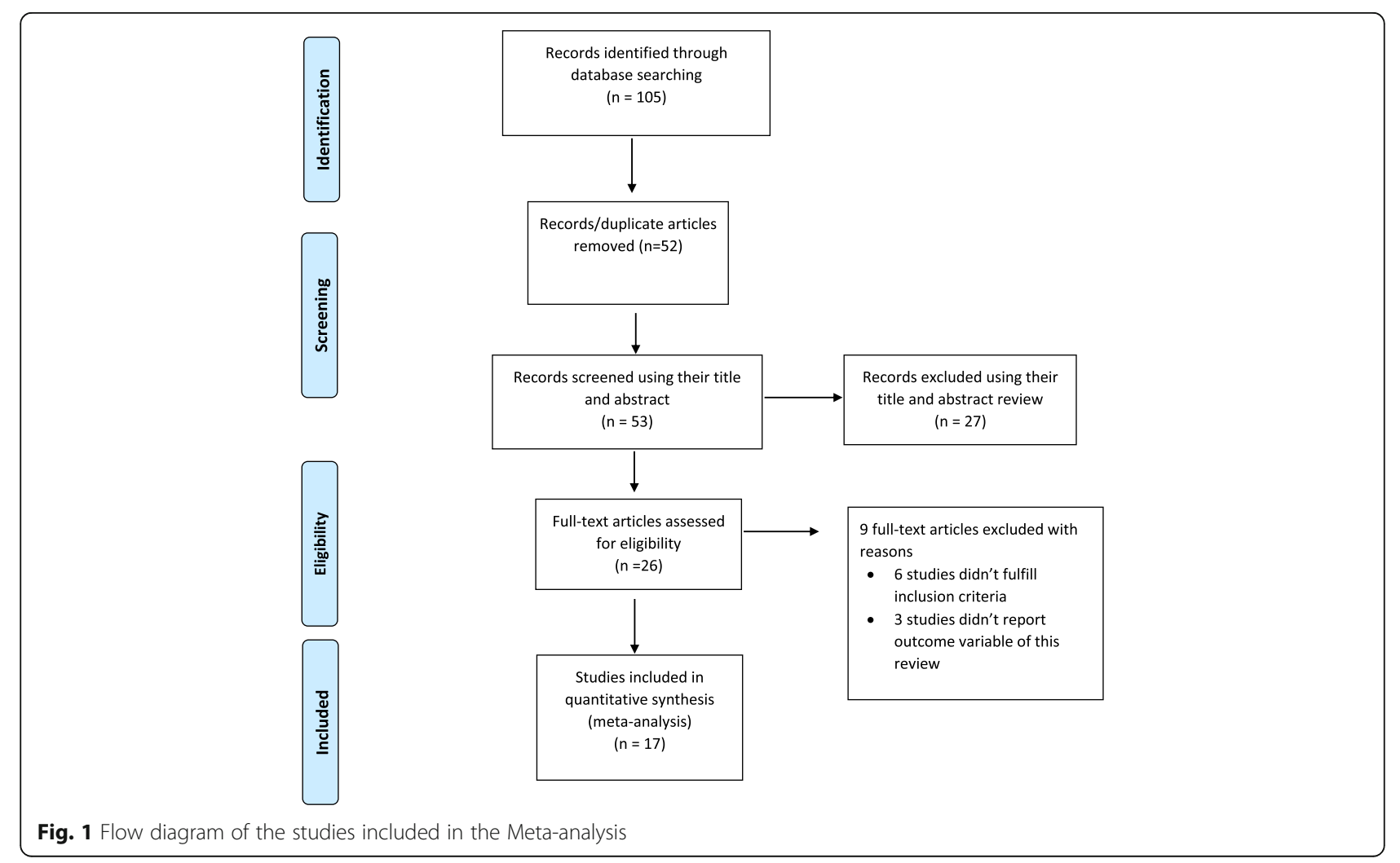


contacting authors through email, totally 105 articles were retrieved. Out of these, 52 duplicate records were removed from the review. Seventeen and ten articles were excluded by reviewing the title and abstract respectively. After a full review of articles, nine were excluded. Six studies didn't fulfill the inclusion criteria and 3 articles fail to report the outcome variables. Finally, seventeen studies were included in this meta-analysis (Fig. 1).

\section{Description of studies}

Thirteen of the included studies were Cross-sectional and four were case-control studies. Most of the regions in Ethiopia were represented in this review. Five studies were conducted in Addis Ababa city, five studies from Amhara region, two from Oromia region, three studies were conducted in SNNPR, one from Tigray and one was a nation based study. Studies were conducted from
1990 to 2016. The sample size of studies ranges from 291 a study conducted in Addis Ababa City(37)to a maximum of 174,561 , a nation based study [19]. Overall, this review included a total of 258,602 pregnant women in Ethiopia (Table 1).

\section{Prevalence of HDP in Ethiopia}

A wide-ranging prevalence of HDP was observed across the different studies included in this review. A prevalence of $1.2 \%$ in nation based study(19)to $18.25 \%$ in SNNPR were observed [25]. The $I^{2}$ test result showed high heterogeneity $\left(\mathrm{I}^{2=} 99.4 \%, p\right.$-value $\left.=<0.001\right)$, which is indicative to use random effects model of analysis. So, using the random effect analysis, the overall pooled prevalence of hypertensive disorder of pregnancy in Ethiopia was 6.07\% (95\% CI: 4.83\%, 7.31\%) (Fig. 2).

Table 1 Summary of characteristics of studies included in the meta-analysis

\begin{tabular}{|c|c|c|c|c|c|c|c|}
\hline S.No & Author/s & Studyyear & $\begin{array}{l}\text { Study } \\
\text { design }\end{array}$ & $\begin{array}{l}\text { Sample } \\
\text { size }\end{array}$ & SE & Study area & $\begin{array}{l}\text { Prevalence of HDP } \\
(95 \% \mathrm{Cl})\end{array}$ \\
\hline 1. & Mekbeb and Ketsela & 1991 & $\begin{array}{l}\text { Cross- } \\
\text { sectional }\end{array}$ & 6766 & 0.255 & Yekatit 12 Hospital, Addis Ababa & $5.14[4.64,5.64]$ \\
\hline 2. & Wolde et al. & 2011 & $\begin{array}{l}\text { Cross- } \\
\text { sectional }\end{array}$ & 1863 & 0.646 & $\begin{array}{l}\text { Jimma University Specialized Hospital, } \\
\text { Oromia Region }\end{array}$ & $8.50[7.23,9.77]$ \\
\hline 3. & Terefe et al. & 2015 & $\begin{array}{l}\text { Cross- } \\
\text { sectional }\end{array}$ & 8626 & 0.208 & DebreBerhan Hospital, Amhara Region & $3.90[3.49,4.31]$ \\
\hline 4. & Vata et al. & 2015 & $\begin{array}{l}\text { Cross- } \\
\text { sectional }\end{array}$ & 7702 & 0.168 & Dilla University Referral Hospital, SNNPR & $2.23[1.90,2.56]$ \\
\hline 5. & Tessema et al. & 2015 & $\begin{array}{l}\text { Cross- } \\
\text { sectional }\end{array}$ & 490 & 1.253 & Dessie hospital, Amhara Region & $8.40[5.94,10.86]$ \\
\hline 6. & Teklu and Gaym & 2006 & $\begin{array}{l}\text { Cross- } \\
\text { sectional }\end{array}$ & 3424 & 0.382 & TikurAnbessa Hospital, Addis Ababa & $5.30[4.55,6.05]$ \\
\hline 7. & Hailu and Kebede & 1991 & $\begin{array}{l}\text { Cross- } \\
\text { sectional }\end{array}$ & 576 & 1.374 & Shiwa, Amhara Region & $12.20[9.51,14.89]$ \\
\hline 8. & Wagnew et al. & 2016 & $\begin{array}{l}\text { Cross- } \\
\text { sectional }\end{array}$ & 42,963 & 0.097 & Government hospitals, Addis Ababa & $4.20[4.01,4.39]$ \\
\hline 9. & Seyom et al. & 2015 & $\begin{array}{l}\text { Cross- } \\
\text { sectional }\end{array}$ & 5415 & 0.208 & Mettu Karl Hospital, Oromia Region & $2.40[1.99,2.81]$ \\
\hline 10. & $\begin{array}{l}\text { Selamawit D and } \\
\text { Sisay } T\end{array}$ & 2015 & $\begin{array}{l}\text { Cross- } \\
\text { sectional }\end{array}$ & 3488 & 0.438 & Zewditu Memorial Hospital, Addis Ababa & $7.20[6.34,8.06]$ \\
\hline 11. & $\begin{array}{l}\text { Shambel W and } \\
\text { Surender R }\end{array}$ & 2016 & $\begin{array}{l}\text { Cross- } \\
\text { sectional }\end{array}$ & 320 & 1.58 & Dessie referral Hospital, Amhara Region & $8.80[5.70,11.90]$ \\
\hline 12. & Shegaze et al. & 2016 & $\begin{array}{l}\text { Cross- } \\
\text { sectional }\end{array}$ & 422 & 1.88 & $\begin{array}{l}\text { Public Health Institutions in Arba Minch, } \\
\text { SNNP Region }\end{array}$ & $18.25[14.57,21.93]$ \\
\hline 13. & Gaym et al. & 2011 & $\begin{array}{l}\text { Cross- } \\
\text { sectional }\end{array}$ & 174,561 & 0.026 & hospitals and health centers in Ethiopia & $1.2[1.15,1.25]$ \\
\hline 14. & Teklit G et al. & 2016 & $\begin{array}{l}\text { Case- } \\
\text { control }\end{array}$ & 291 & - & $\begin{array}{l}\text { ZewdituMemorial hospital and Gandhi Memorial } \\
\text { hospital, Addis Ababa }\end{array}$ & - \\
\hline 15. & Yohannes T et al. & 2016 & $\begin{array}{l}\text { Case- } \\
\text { control }\end{array}$ & 400 & - & Tigray zonal Public Hospitals, Tigray Region & - \\
\hline 16. & Getinet A et al. & 2016 & $\begin{array}{l}\text { Case- } \\
\text { control }\end{array}$ & 464 & - & DerashieWoreda, SNNP Region & - \\
\hline 17. & Aklilu A et al. & 2016 & $\begin{array}{l}\text { Case- } \\
\text { control }\end{array}$ & 831 & - & $\begin{array}{l}\text { BahrDar, Debre Markos, Gondar University hospitals, } \\
\text { Amhara region }\end{array}$ & - \\
\hline
\end{tabular}




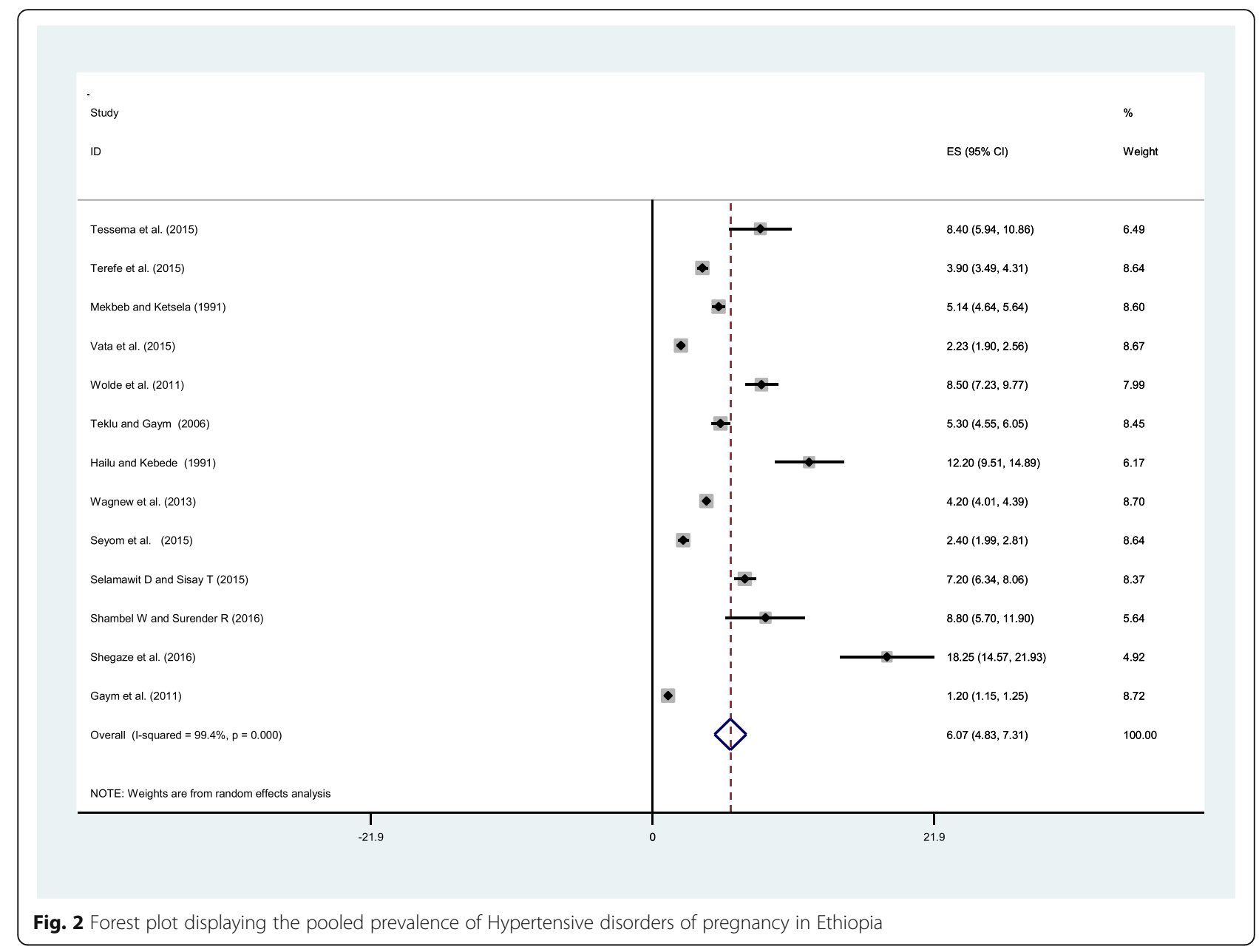

\section{Subgroup analysis}

Subgroup meta-analysis of the prevalence of HDP by region showed a higher pooled prevalence of HDP in SNNPR, $10.13 \%(95 \% \mathrm{CI}=(8.5,12.43))$ and Amhara region, $8.21 \%(95 \% \mathrm{CI}=(3.94,12.48))$. The lowest prevalence, $5.41 \%(95 \% \mathrm{CI}=(4.30,6.51))$ was observed in Addis
Ababa City, capital City of Ethiopia. The subgroup analysis by publication year showed a decrease in the prevalence of HDP from 1990's to 2016in Ethiopia. Studies conducted during 1990 to 2000 showed a higher prevalence, 8.54\% $(95 \% \mathrm{CI}=(1.63,15.45)$ reducing to $5.71 \%(95 \% \mathrm{CI}=(4.37$, 7.06) during the year 2011 to 2016 (Table 2).

Table 2 Sub-group analysis of prevalence of HDP in Ethiopia by region and year of publication

\begin{tabular}{|c|c|c|c|c|}
\hline Sub group & $\begin{array}{l}\text { Number of } \\
\text { studies included }\end{array}$ & Prevalence (95\% Cl) & Test of heterogeneity, $\left.\right|^{2}$ & $p$-value \\
\hline \multicolumn{5}{|l|}{ By region } \\
\hline Addis Ababa City & 4 & $5.41(4.30,6.51)$ & 94.8 & $<0.001$ \\
\hline Amhara region & 4 & $8.21(3.94,12.48)$ & 94.6 & $<0.001$ \\
\hline Oromia region & 2 & $5.42(3.7,7.63)$ & 98.8 & $<0.001$ \\
\hline SNNPR & 2 & $10.13(8.5,12.43)$ & 94.8 & $<0.001$ \\
\hline Nation based study & 1 & $1.20(1.15,1.25)$ & - & - \\
\hline \multicolumn{5}{|l|}{ By publication year } \\
\hline 1990-2000 & 2 & $8.54(1.63,15.45)$ & 96.1 & $<0.001$ \\
\hline $2001-2010$ & 1 & $5.30(4.55,6.05)$ & - & - \\
\hline $2011-2016$ & 10 & $5.71(4.37,7.06)$ & 99.4 & $<0.001$ \\
\hline
\end{tabular}


Table 3 Sub-group analysis of prevalence of HDP in Ethiopia by types of HDP

\begin{tabular}{|c|c|c|c|c|}
\hline Sub group & $\begin{array}{l}\text { Number of } \\
\text { studies included }\end{array}$ & Prevalence $(95 \% \mathrm{Cl})$ & Test of heterogeneity, $\left.\right|^{2}$ & $p$-value \\
\hline \multicolumn{5}{|l|}{ By classification of HDP } \\
\hline $\mathrm{PIH}$ & 7 & $6.29(4.60,7.97)$ & 99.5 & $<0.001$ \\
\hline Including Chronic HTN & 6 & $5.79(4.07,7.51)$ & 97.3 & $<0.001$ \\
\hline \multicolumn{5}{|l|}{ By type of HDP } \\
\hline Pre-eclampsia and eclampsia & 6 & $5.47(3.71,7.22)$ & 99.6 & $<0.001$ \\
\hline Pre-eclampsia and gestational HTN & 1 & $12.2(9.51,14.89)$ & - & - \\
\hline All types of HDP & 6 & $5.79(4.07,7.51)$ & 97.3 & $<0.001$ \\
\hline
\end{tabular}

From the thirteen articles included for the prevalence study, seven assessed PIH while six studies showed the prevalence of HDP including chronic hypertension. The subgroup analysis by classification of HDP showed a prevalence of $\mathrm{PIH}, 6.29 \%(95 \% \mathrm{CI}=(4.60,7.97)$ and HDP including chronic hypertension, $5.79 \%(95 \% \mathrm{CI}=(4.07$, 7.51). Further analysis of types of HDP also showed a pooled prevalence of pre-eclampsia/eclampsia of $5.47 \%$ $(95 \% \mathrm{CI}=(3.71,7.22)($ Table 3$)$.

\section{Association between maternal age and HDP}

Five studies were included in this category of metaanalysis [20, 24, 37-39]. Only one of the included studies(38)showed a higher risk of HDP among young women (less than 20 years old) compared to the adult women (aged 20-34 years old). While four studies $[20,24,37,39]$ showed no difference in the rate of HDP between the two groups. The final pooled meta regression analysis showed no statistically significant difference in the rate of HDP between the young and adult women, $\mathrm{OR}=2.92(95 \% \mathrm{CI}=(0.88,9.70))$. High heterogeneity was observed in this category of metaanalysis, $I^{2}=89 \%, P$-value $=<0.001$. However, the test for publication bias using the Egger's test showed non-statistical significant publication bias, $p$-value $=$ 0.151 (Fig. 3).

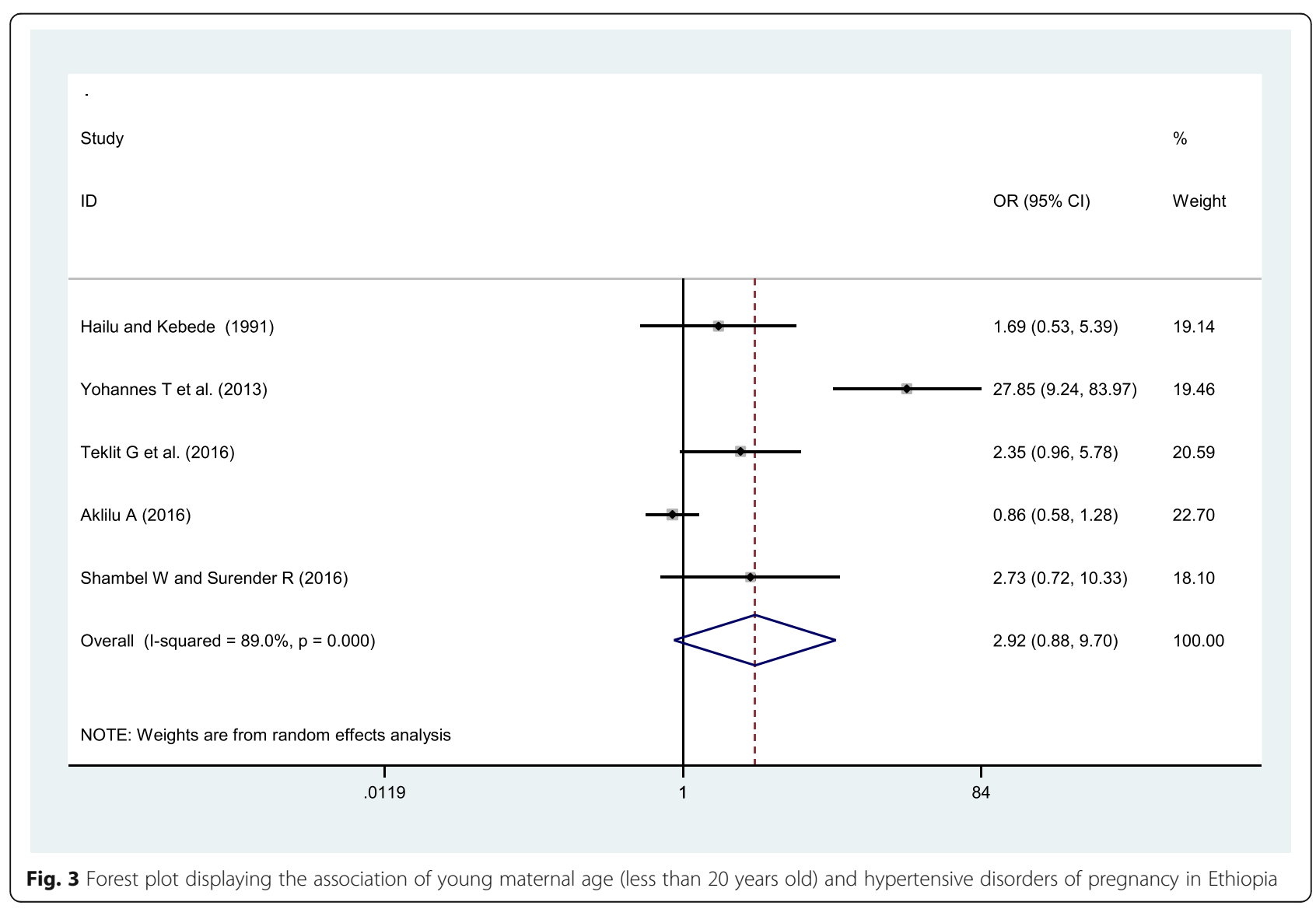


This review also assessed the association of older maternal age ( $>=35$ years old) and adult women (aged 2034 years old) with HDP. The pooled regression analysis result of five studies [20, 24, 37-39] showed a higher risk of HDP among older women compared to adult women, $\mathrm{OR}=1.64(95 \% \mathrm{CI}=(1.18,2.28))$. The heterogeneity test of studies and test for publication bias using the Egger's test showed non-significant heterogeneity $\left(I^{2}=21.5 \%\right.$, p-value $\left.=0.278\right)$ and non-significant publication bias ( $\mathrm{p}$-value $=0.098)$ (Fig. 4).

\section{Gravidity and HDP}

In this subcategory analysis, seven articles were included $[20,24,28,37-40]$. Four of the included studies showed a statistically significant association of primigravida with HDP, higher risk of HDP among primigravida women than multigravida [20, 24, 37, 39]. While, one study [40] showed a lower risk of HDP among primigravida women and two studies $[28,38]$ showed non-significant difference between the two groups. The pooled metaregression analysis showed that there is no statistically significant difference in the occurrence of hypertensive disorders of pregnancy in primigravidae and multigravida women, $\mathrm{OR}=1.37(95 \% \mathrm{CI}=0.78,2.41))$. The studies included in this analysis were heterogeneous as evidenced by $I^{2}\left(I^{2}=90.2 \%, p\right.$-value $\left.=<0.001\right)$ and there is no publication bias as indicated by the Egger's regression test ( $p$-value>0.883). Therefore, random effect model was used to estimate the effect of gravidity on hypertensive disorder of pregnancy (Fig. 5).

\section{Discussion}

Hypertensive disorders of pregnancy are the commonest medical complication of pregnancy. The incidence varies in different populations. Generally, the problem is more common in the developing countries compared to developed countries. In Ethiopia, 19\% of the maternal mortality is caused by HDP [14].

According to the results of this meta-analysis, the pooled prevalence of hypertension disorder of pregnancy in Ethiopia was estimated to be $6.25 \%$ (95\% CI: 5.23\%, 7.26\%). Regional variation in HDP was observed, the highest prevalence of HDP (18.25\%) was reported in a study done in Public Health Institutions in Arba Minch town, SNNPR [41].The lowest prevalence of HDP (1.2\%) was observed in different hospitals and health centers from different regions of Ethiopia [15]. The variation in prevalence of HDP across region might be due to the difference in lifestyle like diet and physical activity and due to the difference in ANC service utilization across

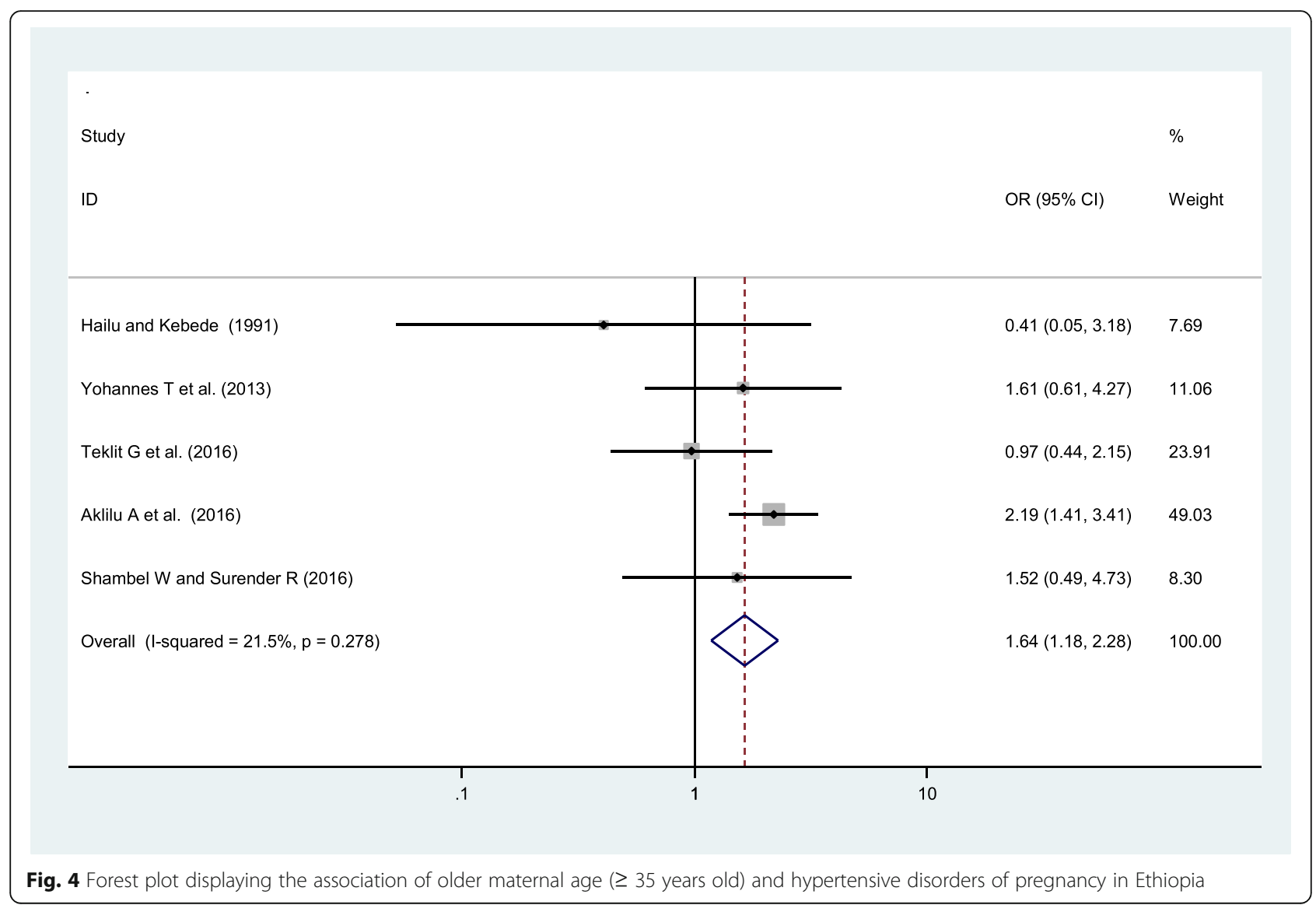




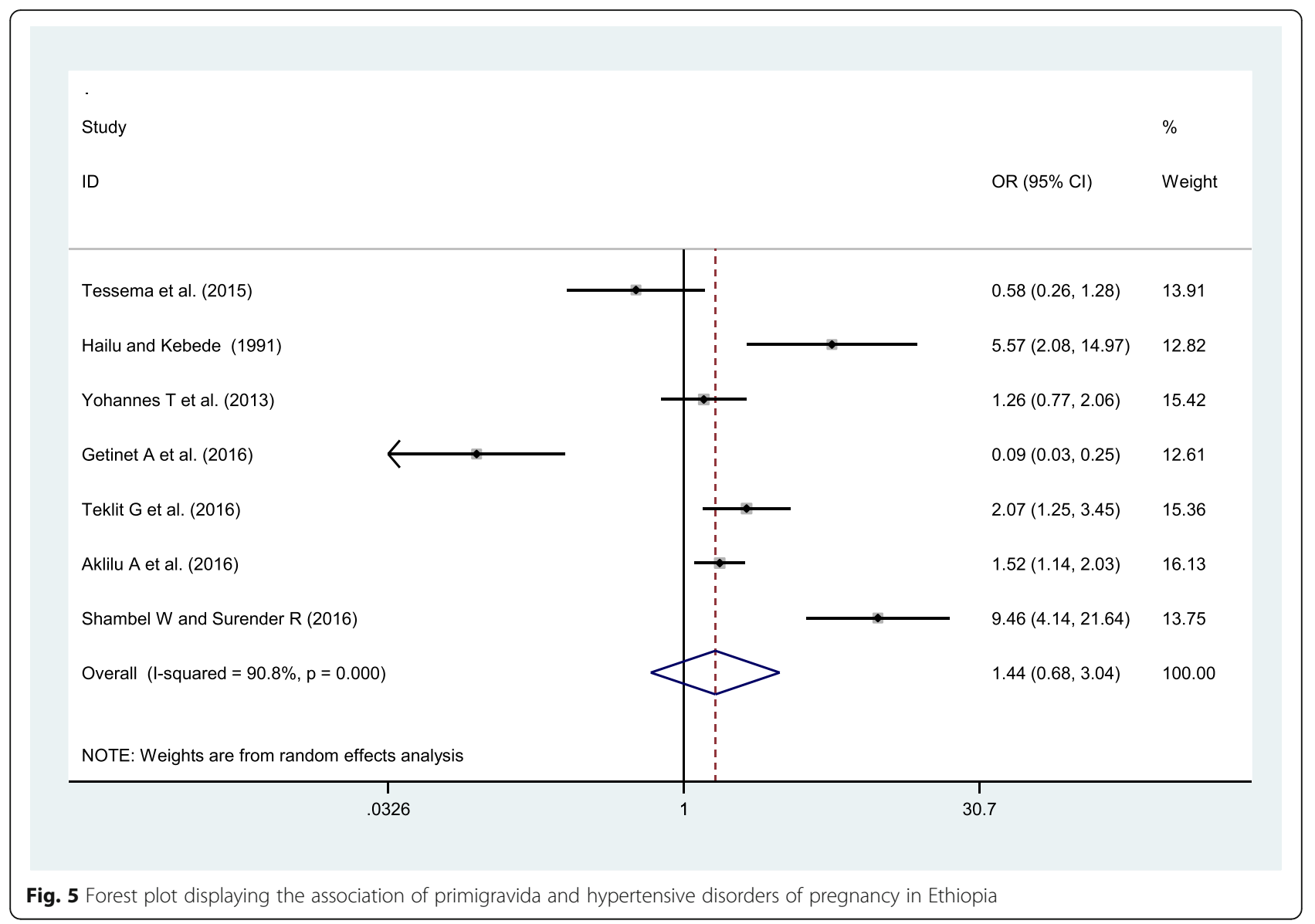

regions. Subgroup analysis findings showed that the prevalence of hypertensive disorders of pregnancy from 1990 up to 2000 and after 2011 was $8.54 \%$ and $5.71 \%$ respectively. This progress in the reduction of prevalence may be due to the improvement in health service coverage, expansion of health extension program and improvement in antenatal care coverage and services in the country.

The overall pooled prevalence of hypertensive disorders of pregnancy in this study is more or less similar to the large study conducted on HDP in China which was estimated 5.2\% [42]. But, the finding is higher than the global prevalence $[43,44]$. This difference might be due to socio-cultural, variability in maternal risk factor distribution, and the difference in antenatal care service accessibility. In addition, most of the studies included in this meta-analysis were conducted in hospitals and health centers which might increase the prevalence.

Young maternal age was not associated with HDP. Similar finding was also observed in a systematic review on pre-eclampsia. The study showed that young maternal age doesn't affect the risk of developing pre-eclampsia [45]. But, other studies showed different findings in the occurrence of HDP among younger and older mothers. For example, studies conducted in Nigeria, Cameroon, and
Brazil showed a higher risk of HDP among young women [46-48]. While, studies conducted in Ontario and South Glamorgan region of Wales showed a lower risk of HDP among young mothers than older women $[49,50]$. The difference between this review and other studies could be attributed to the difference in sociodemographic characteristics and the difference in the age classification for the younger and adult/older maternal age group.

The finding of this meta-analysis also showed a significant association of hypertensive disorders of pregnancy with increasing age. Women aged more than 35 years old were 1.64 times more likely to develop HDP than women aged 20-34 during their pregnancy. The increasing risk of HDP in older mothers could be related to the abnormally high lipid profile, high-density lipid cholesterol, and higher risk of vascular damage in this age group compared to younger women [51, 52]. According to one of a study conducted in Addis Ababa, Ethiopia showed the most common Metabolic syndrome components among women using the ATP III criteria were High-Density Lipid concentration (23.2\%) and abdominal obesity (19.6\%) and it is higher among older women compared to young women [53]. A 4\% rising risk in the rate of late pre-eclampsia and gestational hypertension 
for every year above the age of 32 years was also observed in a study conducted in United Kingdom [54].

A systematic review of controlled studies to assess the risk factors for pre-eclampsia at antenatal booking also showed that, women aged $\geq 40$ were almost two times more likely to develop pre-eclampsia than younger women, irrespective of their previous history of pregnancy [45].Similar findings were also observed in studies conducted in United States, a review conducted by WHO, a study conducted in Asian population and in Latin America and Caribbean women [52, 55-58]. A survey on HDP in China also showed an increasing prevalence of HDP in pregnant women aged 40 years and older than pregnant women aged $25-29$ years, $12.73 \%$ and $4.33 \%$ respectively [59].

Gravidity was not found associated with HDP in the current review. This finding is inconsistent with other studies $[52,59,60]$. The number of studies included in this meta-analysis is small. This may be the reason for the absence of an association between gravidity and HDP. The other reason may be the category of gravidity used in this study. Studies included in this review didn't classify the gravidity into primigravida, multigravida, and grand multigravida. This classification may have masked the association. But, other studies showed that grandmultigravida is at increased risk of HDP [59].

A comprehensive search strategy was employed to retrieve both published and unpublished studies. PRISMA guideline was followed during the review process. This review assessed the association of maternal age with HDP. But, factors associated with HDP are not limited to maternal age and gravidity. So, further wide-scale studies and reviews are needed to assess the association of maternal socioeconomic and use of antenatal care with HDP.

\section{Conclusion}

Even though there is a reduction in the rate of hypertensive disorders of pregnancy in the country, the rate of reduction is very low. HDP is still a common pregnancyrelated disorder in Ethiopia. The problem is higher among older women aged $\geq 35$ years old compared adult women aged 20 to 34 years old. While young maternal age showed no association with the occurrence of HDP. Gravidity was also not associated with HDP.

Therefore, early detection and treatment for HDP are needed for pregnant mothers aged $\geq 35$ years old. Further study to assess the association between gravidity and HDP in Ethiopia are also needed. Government and other stakeholders should give due attention to early screening and treatment of HDP. Community based approaches to diagnose and treat the problem is recommended. Further nation based studies and reviews are needed to show the association of HDP with other socio-demographic, maternal and health service related factors.

\section{Abbreviations}

ANC: Antenatal care; ATP: Adenosine Triphosphate; Cl: Confidence Interval; EDHS: Ethiopian Demographic and Health Survey; HDP: Hypertensive Disorders of Pregnancy; JBI-MAStARI: Joanna Briggs Institute Meta-Analysis of Statistics Assessment and Review Instrument; OR: Odds ratio; PIH: Pregnancy induced hypertension; SE: Standard Error; SNNPR: Southern Nations, Nationalities, and Peoples' Region of Ethiopia; WHO: World Health Organization

\section{Acknowledgements}

We would like to acknowledge to authors of studies included in this review.

\section{Authors' contribution}

All authors involved in the design, selection of articles, data extraction, statistical analysis and manuscript writing. All authors read and approved the final draft of the manuscript.

\section{Funding}

No funding was obtained for this study

Availability of data and materials

All data pertaining to this study are contained and presented in this document.

Ethics approval and consent to participate

Not applicable

Consent for publication

Not applicable

Competing interests

No competing of interest

\section{Publisher's Note}

Springer Nature remains neutral with regard to jurisdictional claims in published maps and institutional affiliations.

\section{Author details}

${ }^{1}$ College of Medicine and Health science, Adigrat University, Tigray, Ethiopia. ${ }^{2}$ College of Health Sciences, Debre Markos University, Debre Markos, Ethiopia. ${ }^{3}$ School of Public Health, College of Medicine and Health Sciences, Bahir Dar University, P.O.Box 79, Bahir Dar, Ethiopia. ${ }^{4}$ Department of Epidemiology and Biostatistics, Institute of public health, University of Gondar, Gondar, Ethiopia.

Received: 7 February 2017 Accepted: 11 January 2018

Published online: 18 January 2018

\section{References}

1. WS CXK, Smith G, Yang Q, Walker M. Pregnancy-induced Hypertension is associated with lower infant mortality in preterm singletons. BJOG. 2006; 113(5):544-51.

2. WHO. Health topics. Maternal Health. Available at http://www.who.int/ topics/maternal_health/en/. Date accessed 19 AUG 2017. 2017.

3. WHO, UNICEF. Managing complications in pregnancy and childbirth: a guide for midwives and doctors. 2017.

4. Yigzaw M, Zakus D, Tadesse Y, Desalegn M, Fantahun M. Paving the way for universal family planning coverage in Ethiopia: an analysis of wealth related inequality. Int J Equity Health. 2015;14(1):77.

5. USAID. Africa bureau. Three successful sub-Saharan Africa family planning programs: Ethiopia, Malawi, Rwanda. Washington, DC: USAID; 2012.

6. Duley L. The global impact of pre-eclampsia and eclampsia. Semin Perinatol. 2009 Jun;33(3):130-7. https://doi.org/10.1053/j.semperi.2009.02.010.

7. WHO; Recommendations for Prevention and Treatment of Preeclampsia and Eclampsia. Department of Maternal and Child Health; 2011.

8. Ngoc, N.T.N., Merialdi, M., Abdel-Aleem, H., Carroli, G., Purwar, M., Zavaleta, N., et al. (2011) Causes of stillbirths and early neonatal deaths: data from 7993 pregnancies in six developing countries. Bulletin of the World Health Organization, 84, 699-705. http://dx.doi.org/https://doi.org/10.2471/BLT.05. 027300 
9. J. M. Roberts, G. Pearson, J. Cutler, and M. Lindheimer, "Summary of the NHLBI Working Group on research on hypertension during pregnancy," Hypertension, vol. 41, no. 3 I, pp. 437-445, 2003.

10. Lakew Y, Reda AA, Tamene H, Benedict S, Deribe K. Geographical variation and factors influencing modern contraceptive use among married women in Ethiopia: evidence from a national population based survey. Reprod Health. 2013;10(1):52

11. Moodley J. Maternal deaths associated with hypertensive disorders of pregnancy: a opulation-based study. Hypertension in pregnancy. 2004;23(3):247-56.

12. Ethiopian Ministry of Health. Costed Implementation Plan for Family Planning in Ethiopia, 2015/16-2020. Retrived on 20 August 2017; from http://www. healthpolicyplus.com/ns/pubs/2021-2030_EthiopiaCIPNov.pdf. 2016.

13. The Federal Democratic Republic of Ethiopia Ministry of Health. Health Sector Transformation Plan. Accessed on 20 August 2017; from http:// globalfinancingfacility.org/sites/gff_new/files/documents/HSTP\%20Ethiopia. pdf. 2015

14. Berhan Y, Berhan A. Causes of maternal mortality in Ethiopia: a significant decline in abortion related death. Ethiopian journal of health sciences. 2014; 24:15-28.

15. Vata PK, Chauhan NM, Nallathambi A, Hussein F. Assessment of prevalence of preeclampsia from Dilla region of Ethiopia. BMC Res Notes. 2015;8(816)

16. Asnake Hailu and Derege Kebede; determinants of pre-eclampsia and gestational hypertension; Ethiopian J.Health Dev. 1991, Vol.5, No.1.

17. Abate M, Lakew Z. Eclampsia a 5 years retrospective review of 216 cases managed in two teaching hospitals in Addis Ababa. Ethiop Med J. 2006; 44(1):27-31

18. Endeshaw G, Berhan Y. Perinatal outcome in women with hypertensive disorders of pregnancy: a retrospective cohort study. International scholarly research notices. 2015;2015(208043)

19. Gaym A, Bailey P, Pearson L, Admasu K, Gebrehiwot Y. Disease burden due to pre-eclampsia/eclampsia and the Ethiopian health system's response. Int J Gynecol Obstet. 2011;115(1):112-6.

20. Hailu A, Kebede D. Determina nts of pre-eclampsia and gestational hypertension. The Ethiopian Journal of Health Development (EJHD). 1991;5(1).

21. Mekbeb T, Ketsela K. Pre-eclampsia/eclampsia at Yekatit 12 Hospital, Addis Ababa, Ethiopia (1987-1989). East Afr Med J. 1991;68(11):893-9.

22. Selamawit $D$, Sisay T. Maternal and Perinatal outcomes of pregenancies complecated by preeclampsia/eclampsia at zewditu memorial hospital. Addis Ababa Aniversity school of graduate studies faculty of Medicine. 2015;

23. Seyom E, Abera M, Tesfaye M, Fentahun N. Maternal and fetal outcome of pregnancy related hypertension in Mettu Karl referral hospital, Ethiopia. Journal of ovarian research. 2015;8(10)

24. Shambel W, Surender R. Hypertensive Disorders of pregnancy and associated factors among admitted pregnant cases in dessie town referral hospital, north east ethiopia. Medico Research Chronicles. 2016;3(3):297-306.

25. Shegaze M, Markos Y, Estifaons W, Taye I, Gemeda E. Magnitude and associated factors of preeclampsia among pregnant women who attend antenatal Care Service in Public Health Institutions in Arba Minch town, southern Ethiopia, 2016. Gynecol Obstet (Sunnyvale). 2016;6(419):2161-0932. 1000419.

26. Teklu S, Gaym A. Prevalence and Clinical correlates of the hypertensive disorders of pregnancy at Tikur Anbessa hospital, Addis Ababa, Ethiopia. Ethiop Med J. 2006:44(1):17-26

27. Terefe W, Getachew Y, Hiruye A, Derbew M, Hailemariam D, Mammo D, et al. Patterns of hypertensive disorders of pregnancy and associated factors at Debre Berhan referral hospital, north Shoa, Amhara region. Ethiop Med J. 2015;53

28. Tessema GA, Tekeste A, Ayele TA. Preeclampsia and Associated factors among pregnant women attending antenatal care in Dessie referral hospital, Northeast Ethiopia: a hospital-based study. BMC Pregnancy and Childbirth. 2015;15(1):73.

29. Vata PK, Chauhan NM, Nallathambi A, Hussein F. Assessment of prevalence of preeclampsia from Dilla region of Ethiopia. BMC research notes. 2015;8(1):816

30. Wagnew M, Dessalegn M, Worku A, Nyagero J. Trends Of preeclampsia/ eclampsia and maternal and neonatal outcomes among women delivering in addis ababa selected government hospitals, Ethiopia: a retrospective cross-sectional study. The Pan African medical journal. 2016;25(Suppl 2)

31. Wolde Z, Segni H, Woldie M. Hypertensive disorders of pregnancy in Jimma University specialized hospital. Ethiopian journal of health sciences. $2011 ; 21(3)$
32. Addis Ababa University Institutional Repository. Retrived on December 25/ 2016 from: http://etd.aau.edu.et/handle/123456789/1557 [Internet].

33. Davey D, MacGillivray I. The classification and definition of the hypertensive disorders of pregnancy: proposals submitted to the international society for the study of hypertension in pregnancy. Clinical and Experimental Hypertension Part B: Hypertension in Pregnancy. 1986;5(1):97-133.

34. The FIGO textbook of pregnancy hypertension. An evidence-based guide to monitoring, prevention and management. Accessed from; www.glowm.com/ pdf/NEW-Pregnancy_Hypertension-apendix.pdf on 19 August 2017. 2017.

35. Munn Z, Moola S, Lisy K, Riitano D. The Joanna Briggs Institute Reviewers' Manual 2014. The systematic review of prevalence and incidence data. Adelaide, SA: The Joanna Briggs Institute. 2014.

36. Higgins JP, Thompson SG, Deeks JJ, Altman DG. Measuring inconsistency in meta-analyses. BMJ: British Medical Journal. 2003;327(7414):557.

37. Teklit G, Abiy S. F M. Risk factors for preeclampsia among women attending delivery services in selected public hospitals in Addis Ababa,Ethiopia. School of graduate studies, Addis Ababa University. 2016:

38. Tesfay $Y$, Berhe $S$, Aregay A. Risk Factors of pregnancy related hypertension among women attending maternal health care service in selected public hospitals of tigray, ethiopia. International Journal of Development Research. Aug, 2016;06(08):8904-11.

39. Almaz A, Gedefaw A, Muluken A. Determinants of Preeclampsia in Amhara region; A case-control study. Msc thesis2016.

40. Getinet A, Seblewengel L. A E. Factors Associated With hypertension during pregnancy in Derashie Woreda South Ethiopia, case control. Qual Prim Care. 2016;24(5):207-13.

41. Shegaze M, Markos Y, Estifaons W, Taye I. Magnitude and associated factors of preeclampsia among pregnant women who attend antenatal Care Service in Public Health Institutions in Arba Minch town, southern Ethiopia, 2016. Gynecology \& Obstetrics. 2016;6(12)

42. un Ye etal C. The 2011 survey on hypertensive disorders of pregnancy (HDP) in China: prevalence, risk factor s, complications, pregnancy and perinatal outcomes. PLOS June. 2014;9(6)

43. Carmen Dolea, Carla AbouZahr; Global burden of hypertensive disorders of pregnancy in the year 2000 accessed on date 24/01/2017 at http://apps. who.int/healthinfo/statistics/bod_hypertensivedisordersofpregnancy.pdf.

44. Abalos E, Cuesta etal C. Pre-eclampsia, eclampsia and adverse maternal and perinatal outcomes: a secondary analysis of the World Health Organization multi-country survey on maternal and newborn health. World Health Organization. 2014;

45. Duckitt K, Harrington D. Risk factors for pre-eclampsia at antenatal booking: systematic review of controlled studies. BMJ. 2005;330(7491):565.

46. Ayuba II, Outcome GO. Of teenage pregnancy in the niger delta of Nigeria. Ethiop J Health Sci. 2012;22(1):45-50.

47. Ngowa JDK, Kasia JM, Pisoh WD, Ngassam A, Noa C. Obstetrical and perinatal outcomes of adolescent pregnancies in Cameroon: a retrospective cohort study at the Yaoundé general hospital. Open Journal of Obstetrics and Gynecology. 2015;5(02):88.

48. Oliveira FC, Surita FG, Silva JLP e, Cecatti JG, Parpinelli MA, Haddad SM, et al. Severe maternal morbidity and maternal near miss in the extremes of reproductive age: results from a national cross-sectional multicenter study. BMC pregnancy and childbirth. 2014;14(1):77.

49. Fleming $\mathrm{N}, \mathrm{Ng} \mathrm{N}$, Osborne C, Biederman S, Yasseen AS 3rd, Dy J, et al. Adolescent pregnancy outcomes in the province of Ontario: a cohort study. Journal of obstetrics and gynaecology Canada : JOGC = Journal d'obstetrique et gynecologie du Canada : JOGC. 2013;35(3):234-45.

50. Gupta N, Kiran U, Bhal K. Teenage pregnancies: obstetric characteristics and outcome. Eur J Obstet Gynecol Reprod Biol. 2008;137(2):165-71.

51. Kolovou GD, Bilianou HG. Influence of aging and menopause on lipids and lipoproteins in women. Angiology. 2008;59(2_suppl):54S-7S.

52. Bilano VL, Ota E, Ganchimeg T, Mori R, Souza JP. Risk factors of preeclampsia/eclampsia and its adverse outcomes in low- and middle-income countries: a WHO secondary analysis. PLoS One. 2014;9(3):e91198.

53. Tran A, Gelaye B, Girma B, Lemma S, Berhane $Y$, Bekele T, et al. Prevalence of metabolic syndrome among working adults in Ethiopia. Int J Hypertens. 2011;2011

54. Poon L, Kametas N, Chelemen T, Leal A, Nicolaides K. Maternal risk factors for hypertensive disorders in pregnancy: a multivariate approach. J Hum Hypertens. 2010;24(2):104.

55. Bianco A, Stone J, Lynch L, Lapinski R, Berkowitz G, Berkowitz RL. Pregnancy outcome at age 40 and older. Obstet Gynecol. 1996;87(6):917-22. 
56. Saftlas AF, Olson DR, Franks AL, Atrash HK, Pokras R. Epidemiology of preeclampsia and eclampsia in the United States, 1979-1986. Am J Obstet Gynecol. 1990;163(2):460-5.

57. Lee CJ, Hsieh TT, Chiu TH, Chen KC, Lo LM, Hung TH. Risk factors for preeclampsia in an Asian population. International journal of gynaecology and obstetrics: the official organ of the International Federation of Gynaecology and Obstetrics. 2000;70(3):327-33.

58. Conde-Agudelo A, Belizan JM. Risk factors for pre-eclampsia in a large cohort of Latin American and Caribbean women. BJOG : an international journal of obstetrics and gynaecology. 2000;107(1):75-83.

59. Ye C, Ruan Y, Zou L, Li G, Li C, Chen Y, et al. The 2011 survey on hypertensive disorders of pregnancy (HDP) in China: prevalence, risk factors, complications, pregnancy and perinatal outcomes. PLoS One. 2014;9(6):e100180

60. Reyes LM, García RG, Ruiz SL, Camacho PA, Ospina MB, Aroca G, et al. Risk factors for preeclampsia in women from Colombia: a case-control study. PLoS One. 2012;7(7):e41622.

Submit your next manuscript to BioMed Central and we will help you at every step:

- We accept pre-submission inquiries

- Our selector tool helps you to find the most relevant journal

- We provide round the clock customer support

- Convenient online submission

- Thorough peer review

- Inclusion in PubMed and all major indexing services

- Maximum visibility for your research

Submit your manuscript at www.biomedcentral.com/submit
Biomed Central 